\title{
Development and validation of a Malawian version of the primary care assessment tool

Luckson Dullie $^{1,2,3^{*}}$, Eivind Meland ${ }^{1}, \varnothing$ ystein Hetlevik' ${ }^{1}$ Thomas Mildestvedt ${ }^{1}$ and Sturla Gjesdal ${ }^{1}$

\begin{abstract}
Background: Malawi does not have validated tools for assessing primary care performance from patients' experience. The aim of this study was to develop a Malawian version of Primary Care Assessment Tool (PCAT-Mw) and to evaluate its reliability and validity in the assessment of the core primary care dimensions from adult patients' perspective in Malawi.

Methods: A team of experts assessed the South African version of the primary care assessment tool (ZA-PCAT) for face and content validity. The adapted questionnaire underwent forward and backward translation and a pilot study. The tool was then used in an interviewer administered cross-sectional survey in Neno district, Malawi, to test validity and reliability. Exploratory factor analysis was performed on a random half of the sample to evaluate internal consistency, reliability and construct validity of items and scales. The identified constructs were then tested with confirmatory factor analysis. Likert scale assumption testing and descriptive statistics were done on the final factor structure. The PCAT-Mw was further tested for intra-rater and inter-rater reliability.
\end{abstract}

Results: From the responses of 631 patients, a 29-item PCAT-Mw was constructed comprising seven multi-item scales, representing five primary care dimensions (first contact, continuity, comprehensiveness, coordination and community orientation). All the seven scales achieved good internal consistency, item-total correlations and construct validity. Cronbach's alpha coefficient ranged from 0.66 to 0.91. A satisfactory goodness of fit model was achieved (GFI = 0.90, CFI $=0.91$, RMSEA $=0.05$, PCLOSE $=0.65$ ). The full range of possible scores was observed for all scales. Scaling assumptions tests were achieved for all except the two comprehensiveness scales. Intra-class correlation coefficient (ICC) was 0.90 $(n=44,95 \% \mathrm{Cl} 0.81-0.94, p<0.001)$ for intra-rater reliability and $0.84(n=42,95 \% \mathrm{Cl} 0.71-0.96, p<0.001)$ for inter-rater reliability.

Conclusions: Comprehensive metric analyses supported the reliability and validity of PCAT-Mw in assessing the core concepts of primary care from adult patients' experience. This tool could be used for health service research in primary care in Malawi.

Keywords: Primary care, Primary care assessment tool, Patient centeredness, Patient experience, Primary care quality measurement

\section{Background}

Evidence from both developed and developing countries indicates that well established primary care is the backbone of effective, efficient and equitable health care delivery systems [1-7]. Investing more in primary health care interventions is likely to accelerate progress towards achieving the sustainable development goal of universal

\footnotetext{
* Correspondence: Idullie@pih.org; Luckson.Dullie@student.uib.no 'Department of Global Public Health and Primary Care, University of Bergen, Bergen, Norway

${ }^{2}$ Partners In Health, Neno, Malawi

Full list of author information is available at the end of the article
}

health coverage [8]. A growing focus is also emerging to investigate primary care performance and organization in different settings using data from patients' assessment of service delivery [9-12].

Malawi is a signatory to global declarations on primary health care and has a health sector strategic plan "that is inspired by the primary health care approach" [13]. Malawi's health system is faced with the most severe shortage of healthcare personnel in sub-Saharan Africa with only two (2) physicians and 34 nurse/midwives per 100,000 inhabitants [14]. Mid-level health care workers

(c) The Author(s). 2018 Open Access This article is distributed under the terms of the Creative Commons Attribution 4.0 International License (http://creativecommons.org/licenses/by/4.0/), which permits unrestricted use, distribution, and reproduction in any medium, provided you give appropriate credit to the original author(s) and the source, provide a link to the Creative Commons license, and indicate if changes were made. The Creative Commons Public Domain Dedication waiver (http://creativecommons.org/publicdomain/zero/1.0/) applies to the data made available in this article, unless otherwise stated. 
such as clinical officers and medical assistants form the bulk of the work force as providers of primary care [15]. Most health indicators, while slowly improving, remain poor. Access, equity and financial risk protection are still major challenges [14-16].

There are three levels of health care in Malawi. Primary care consists of dispensaries and health centers which target a coverage radius of $8 \mathrm{~km}$. Secondary level care is provided in district hospitals while tertiary care is delivered in three regional and two mental hospitals. There is an essential health package of services since 2004 that is offered in all public facilities as well as those belonging to the faith based organizations. Patients enter the system at first level and are referred higher up depending on the need [13].

To augment this primary health care structure, Malawi's sole medical school has since 2015 started a specialist family medicine training program to train family physicians who will lead district health systems towards primary health care implementation. This approach is already showing evidence of positive impact on health systems elsewhere in subSaharan Africa [17, 18]. Earlier similar findings have come from developed and mid-level emerging countries like China and Brazil [19].

The Ministry of Health in Malawi has established a memorandum of understanding with the non-governmental organization Partners In Health to use the rural district of Neno in the South-west part of the country as a model of primary care delivery. As a result, novel models of primary care interventions are being implemented in the district to reflect program integration of programmatic interventions, [20] community orientation [21] and financial risk protection [22].

As an integral part of these primary care reforms, there is need for assessment of primary care performance in order to describe, compare and follow-up services from patients' perspectives. Several instruments have been developed in order to make this assessment structured and standardized way in different settings [23-27]. Some instruments assess many aspects of primary care services (or key dimensions) whereas others only target specific dimensions, like accessibility or continuity of care [28].

Within primary health care research, the US Primary Care Assessment Tool (PCAT) has been widely adapted and used in patient surveys in many countries including South Africa [29-34]. Based on the 1994 American Institute of Medicine's definition of primary care [35], the PCAT aims at a global assessment of primary care organizations and their achievements around the core dimensions of accessibility, comprehensiveness, coordination and continuity, and accountability. In addition, it also assesses derivative dimensions of family orientation, community orientation, and cultural competence.

The aim of this study was therefore to develop a reliable and valid instrument that could be used to assess primary care performance from adult patients' perspective of the Malawian health system in order to facilitate future evaluation of heath care services and to compare performance and development over time. The Specific objectives were to adapt the South African PCAT (ZA-PCAT) to the Malawian health system and culture, and to analyze its feasibility, reliability and validity.

\section{Methods}

\section{Instrument}

The ZA-PCAT questionnaire is similar to the original American PCAT. Through 114 items, it measures eight domains of primary care: first contact (access and utilization), on-going care, coordination (patient care and information systems), comprehensiveness (services available and services provided), family orientation, community orientation, cultural competence and primary care team. Each item is answered on a 4-point Likert-type scale $(1=$ definitely not; $2=$ probably not; $3=$ probably; $4=$ definitely) with an additional possibility to respond "not sure". The questionnaire includes 26 additional questions to determine the user's primary care facility/person and socio-demographic data. The ZA-PCAT was chosen for the study because of proximity and similarity of health systems to the study setting. Adapted versions of the PCAT have been used to measure primary care organization and performance, and to assess performance of primary care in different settings [9-11].

\section{Face and content validity}

The cross cultural validation from ZA-PCAT to PCAT-Mw is illustrated in Fig. 1.

Face and content validity of the questionnaire were assessed through a modified Delphi [36] and nominal group technique process [37] using a panel of 9 experts that included 2 primary care providers, 2 primary care managers, 2 primary care policy makers, 2 Family Medicine academics and 1 patient representative. The ZA-PCAT was sent to the 9 experts by e-mail. To assess content validity, each expert was asked to rate each dimension and item for relevance to the Malawi health system on Likert scale: 5 highly relevant, 4 - relevant, 3 - not decided, 2 - not relevant, 1- highly irrelevant. Additionally, experts were asked if items were appropriately phrased and if there were additional dimensions or items to be added. Criteria for retention was at least 7 experts scoring 4 and above while exclusion was when at least 7 experts scored 2 or 1 . Dimension and items with any other score results, additional dimensions and items proposed and suggested rephrasing of items were brought for the nominal group technique session using the same group of experts convened by three of the investigators. During this session, suggested new phrasing and items were discussed and experts were asked to reassess those items that had not 


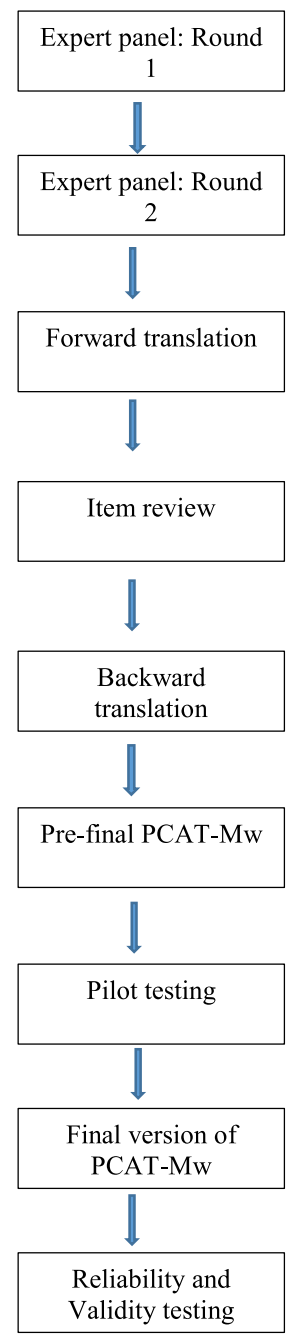

- Delphi process: First round of Face and Content validity

- Nominal Group Technic to build consensus: Second round of face and content validity

- Questionnaire was translated into local Chichewa language by a translator whose native language was Chichewa, the local language.

- Quality review of items by researcher (native Malawian, Chichewa is first language) for evaluation of validity and clarity of translation

- Questionnaire was translated back to English by translator whose native language was English

- Pre-final PCAT-Mw compiled after clarifying differences between forward and backward translators and researcher

- Pre-final questionnaire was tested on randomly selected 30 patients for feasibility and understanding

- A final version was compiled after clarifying issues arising from pilot testing

- Final PCAT-Mw applied to field testing for validity and reliability testing

Fig. 1 Process of cross cultural validation from ZA-PCAT to PCAT-Mw before metric analysis

achieved adequate consensus during the first round. Criteria for inclusion or exclusion were as described above.

For face validity, we used the definition "the degree to which a measurement instrument looks as though it is an adequate reflection of the construct to be measured" [38] and thus asked each expert to indicate whether or not the questionnaire was generally adequate to be used in the Malawian context. Results were collated to form the questionnaire that was to be translated.

\section{Translation and cultural adaptation}

Forward translation was done by a translator whose native language was Chichewa, the most widely spoken national language (used by about $65 \%$ of the population) which was to be used in the study. A review was done by the principal investigator, a native Malawian with Chichewa as first language for clarity of the translation. A backward translation was then done by a translator whose native language was English. Any differences were sorted out through a reconciliation discussion between the translators and the principal investigator.

\section{Feasibility and understanding of the questionnaire- pilot testing}

Six interviewers with prior experience in patient interviews were trained in the PCAT interviews. The interviewers administered the questionnaire to 30 randomly selected patients at Neno district hospital out-patient clinic. In addition to responding to the items, patients were also asked for comprehensibility of the questions, the overall relevance of the items to the Malawi setting and for suggestions for any changes to the wording. The pilot study also assessed how long the questionnaire took to complete and the feasibility of carrying interviews in the out-patient 
clinic. From this phase a version was obtained which was used for the survey.

\section{Data collection, setting and study population}

A cross sectional study was carried out in August September, 2016 in Neno, a rural district in South-West of Malawi with a population of 150,000 people, two hospitals and 11 health centers. Out-patient clinics in the two hospitals and 8 health centers were selected based on high patient volumes. Study participants were at least 18 years of age, must have been using the facility for at least six months and must have visited the facility for at least 3 times. Patients that were acutely ill, frail looking or with severe mental health disorders were excluded in order to allow for the immediate medical attention that they needed. Sample size was calculated based on similar studies using at least 5:1 subject to item ratio [30-34]. Sample size of 600 was targeted. From this it was calculated that each interviewer needed to administer seven questionnaires per day. The sampling frame was the $40-50$ patients waiting to be seen on each working day. These patients were asked for permission to participate in the interview with a full explanation of the research purpose and were told that the survey would not influence their consultation. The sampling interval was calculated by dividing the number of available waiting patients by seven. The random starting point was identified using a smart phone random number generator.

\section{Statistical analysis}

Data were entered into and analyzed using the IBM SPSS Statistics 24.0.0 (2016) package. For consistency with methods used in PCAT studies in other countries, a mid-scale value of 2.5 was assigned to "not sure" answers while the mean item score was used for missing data $[26,29-31]$.

First, each item responses were inspected for floor or ceiling effect and a correlation analysis was run to ensure sufficient correlation between the items.

Secondly, the data file was split randomly into 50\% subsets to allow for exploratory factor analysis with sample 1 and confirmatory factor analysis with sample 2 .

Prior to exploratory factor analysis of sample 1, the overall Kaiser-Meyer-Olkin (KMO) statistic and Bartlett's test for sphericity were calculated to evaluate whether the sample was large enough to perform a satisfactory factor analysis. The KMO statistic is a measure of the shared variance in the items to justify factor analysis. On a range of 0 to 1 , the desirable result is closer to 1 and the minimum recommended value is 0.6 [39]. Bartlett's test is a chi squared test whose null hypothesis states that there are no relationships between the items. A significant test confirms that linear combinations exist between the items and that the matrix is suitable for factor analysis [40].
Factor extraction was done through principal axis factoring and varimax rotation. Principal axis factoring was chosen because it allows for the exploration of underlying constructs, which cannot be measured directly, through items thought to be reflective measures of the construct especially where there are few items per component and low component loadings [41]. Theoretically, oblique rotation should be used in the case where factors were assumed to possess underlying correlations [41]. However, the varimax rotation rendered the matrix more reproducible and easier to interpret.

Determining scale structure and item reduction was based on multiple steps. First the scree plot, which is a graphical representation of the factors and their corresponding eigenvalues, was used. Factors above the bend or elbow cut-off point were retained. Additionally, items were retained when they attained factor loadings of at least 0.32, without cross loadings of the same significance and shared the same underlying meaning of construct and had interitem correlation between 0.2 and 0.5 .

Next, internal consistency was assessed by Cronbach's alpha and item-total correlation. For a scale to be considered sufficiently reliable, minimum Chronbach's alpha value of 0.5 is accepted as adequate. Within the scale, all the retained items were to exceed the minimum acceptable item-total correlation of 0.30 [39].

Likert scaling assumptions were tested by assessment of equal item convergence through the range of item-total correlation; domain score reliability through Cronbach's alpha; item-convergent validity through item-scale correlations (minimum 0.3); and item-discriminant validity using scaling success rate (correlation of each item with other items within the same scale being greater than with items from different scales).

Construct validity was analyzed throughout the measures of convergent validity and discriminant validity explained above. Further construct cross-validation was done through confirmatory factor analysis (CFA) using IBM Amos Graphics package 24.0.0 (2016) on sample 2 which was subjected to structural equation modeling. Maximum likelihood estimation was chosen with output of squared multiple correlations, maximization history, standardized estimates and index modification. The model's overall goodness of fit was assessed using a combination of indices: chi squared test, goodness of fit index (GFI), the root mean square error of approximation (RMSEA), and an incremental fit index, the comparative fit index (CFI). Some authors advocate for an insignificant chi squared test to show model fitness [42]. This is known to be unlikely possible especially when a large sample size is used [43]. The GFI was created as an alternative to the Chi squared test and calculates the proportion of variance that is accounted for by the estimated population covariance. The statistic ranges from 0 to 1 and a minimum cut off of 0.9 is 
recommended [44]. RMSEA estimates how well the model would fit the sample if optimal parameters were available and uses the chi squared statistics taking degrees of freedom into account. Most authors will accept values below 0.08 but recommend those under 0.06 to indicate a sufficient fit between the specified model and the data [45]. The CFI evaluates the difference between an independent model and a specified model without being affected by the sample size and values $>0.9$ are acceptable [45].

Lastly, descriptive statistics were performed for the revised PCAT domains, including the mean, standard deviation, range, skewness and kurtosis. The results of the study were planned for both local and international dissemination through meetings with local authorities, scientific conference presentations and publication in an appropriate journal.

\section{Further reliability tests}

A subset of patients had second interviews after 4 weeks to assess consistency of the item scores through intrarater and inter-rater reliability analysis. To do this 2 of the 10 facilities where data was collected were selected randomly. One was assigned for test -retest intra-rater reliability and patients from this facility were asked to return for a second interview by the same interviewer after 4 weeks. At the inter-rater facility, patients were asked to return after 4 weeks and were interviewed by a different interviewer from the one who did the first. Intra-class correlation coefficient (ICC) was calculated for the sum scores of the domain means of the responses of the participants with the two rounds of interviews to measure intra-rater and inter-rater reliability.

\section{Results}

\section{Face and content validity}

The ZA PCAT was rated to be generally relevant to the Malawi health system. Table 1 compares the item and domain structures of the ZA PCAT and the initial version of the PCAT-Mw. The general structure and content was largely similar. The modified Delphi and nominal group technique process eliminated the domain "primary care team" and modified "coordination - Health information" because patients in Malawi use patient held health passports for their medical records. There was also substitution of services available and provided to fit context in Malawi.

\section{Pilot study}

During the pilot study, it was found that the questionnaire took approximately $45 \mathrm{~min}$ to complete. There were no substantial changes suggested by patients to the content of dimensions or items. All items and dimensions were thought to be relevant to the Malawi setting. Suggestions were however made to the local language translation to
Table 1 Comparison of number of items and structure of ZAPCAT and PCAT-Mw

\begin{tabular}{|c|c|c|c|}
\hline $\begin{array}{l}\text { Parts of the } \\
\text { Questionnaire }\end{array}$ & ZA-PCAT & $\begin{array}{l}\text { PCAT-Mw before } \\
\text { metric analysis }\end{array}$ & $\begin{array}{l}\text { Final } \\
\text { PCAT-Mw }\end{array}$ \\
\hline \multicolumn{4}{|l|}{ Core domains } \\
\hline B - First contact: utilization & 3 & 3 & \\
\hline C - First contact: access & 19 & 18 & 3 \\
\hline D - Continuity of care & 15 & $\begin{array}{l}16 \text { (plus } 2 \text { open } \\
\text { question) }\end{array}$ & 8 \\
\hline E - Coordination & 10 & $\begin{array}{l}9 \text { (plus } 7 \text { open } \\
\text { questions) }\end{array}$ & 3 \\
\hline $\begin{array}{l}\text { F - Coordination - Health } \\
\text { information }\end{array}$ & 3 & 4 & \\
\hline \multicolumn{4}{|l|}{ G - Comprehensiveness } \\
\hline Services available & 28 & 28 & 6 \\
\hline \multicolumn{4}{|l|}{ H - Comprehensiveness } \\
\hline Services provided & 15 & 14 & 6 \\
\hline \multicolumn{4}{|l|}{ Ancillary domains: } \\
\hline I - Family orientation & 3 & 3 & \\
\hline $\mathrm{J}$ - Community orientation & 6 & 6 & 3 \\
\hline K - Cultural competence & 5 & 5 & \\
\hline P - Primary care team & 7 & & \\
\hline $\begin{array}{l}\text { About PC provider } \\
\text { information }\end{array}$ & 8 & 8 & 8 \\
\hline Socio-demographic data & 18 & 18 & 18 \\
\hline Core domains $(\mathrm{B}-\mathrm{H})$ & 93 & 92 & 26 \\
\hline All domains (B-P) & 114 & 106 & 29 \\
\hline Total: & 140 & $\begin{array}{l}132 \text { (plus } 9 \text { open } \\
\text { questions) }\end{array}$ & 47 \\
\hline
\end{tabular}

improve comprehensibility of items in the continuity dimension. A further suggestion concerned timing of interviews to fit better into normal flow of services as patients were waiting to be attended to.

\section{Study participants}

Out of 649 patients approached, 18 (2.8\%) declined to participate in the study. These results are based on 631 completed questionnaires. Missing data accounted for approximately $1.9 \%$ of all data. Table 2 shows the sociodemographic characteristics of the 631 study participants of which $65.1 \%$ were female, $74.1 \%$ were under the age of 40 years and $2.7 \%$ were above 65 years. Education was generally low with $80.9 \%$ having only attended 8 years of primary school or less. We found that $41.7 \%$ of the patients were unemployed themselves while $52.5 \%$ came from homes where the household head was unemployed. Access to safe water and electricity were major challenges as only $21.9 \%$ of households had access to safe water while access to electricity was at $6.3 \%$.

Of the total interviewees, $75.6 \%$ had been in contact with their health center for at least 3 years and $65.9 \%$ 
Table 2 Sociodemographic characteristics of total study subjects $(N=631)$ and comparison of Sample 1 and 2

\begin{tabular}{|c|c|c|c|c|}
\hline & Total sample $(N=631)$ & Sample $1(n=323)$ & Sample $2(n=308)$ & $p$ value \\
\hline \multicolumn{5}{|l|}{ Gender } \\
\hline Male & $220(34.9)$ & $110(34.4)$ & $110(35.7)$ & \multirow[t]{2}{*}{0.37} \\
\hline Female & $411(65.1)$ & $213(65.6)$ & $198(64.3)$ & \\
\hline \multicolumn{5}{|l|}{ Age (years) } \\
\hline Up to 40 & $467(74.1)$ & $242(74.9)$ & $225(73.4)$ & \multirow[t]{3}{*}{0.33} \\
\hline $41-65$ & $146(23.2)$ & $75(23.2)$ & $71(22.9)$ & \\
\hline$>65$ & $18(2.7)$ & $6(1.9)$ & $12(3.7)$ & \\
\hline \multicolumn{5}{|l|}{ Education } \\
\hline$<5$ years of primary school & $271(43.0)$ & $132(40.9)$ & $139(45.1)$ & \multirow[t]{3}{*}{0.14} \\
\hline $6-8$ years of primary school & $239(37.9)$ & $128(39.6)$ & $111(36.4)$ & \\
\hline Attended secondary school & $113(17.9)$ & $60(18.6)$ & $53(17.2)$ & \\
\hline Post-secondary education & $8(1.3)$ & $3(0.9)$ & $5(1.2)$ & 0.36 \\
\hline \multicolumn{5}{|l|}{ Employment } \\
\hline Full time & $54(8.6)$ & $31(9.6)$ & $23(7.5)$ & \multirow[t]{3}{*}{0.17} \\
\hline Part time & $103(16.3)$ & $52(16.1)$ & $51(16.6)$ & \\
\hline Self-employed & $211(33.4)$ & $101(31.3)$ & $110(35.7)$ & \\
\hline Unemployed & $263(41.7)$ & $139(43.0)$ & $124(40.2)$ & 0.24 \\
\hline \multicolumn{5}{|c|}{ Piped water/protected well nearby within compound or nearby } \\
\hline Yes & $138(21.9)$ & $69(21.1)$ & $69(22.4)$ & \multirow[t]{2}{*}{0.35} \\
\hline No & $493(78.1)$ & $254(78.9)$ & $239(77.6)$ & \\
\hline \multicolumn{5}{|l|}{ Electricity in the home } \\
\hline Yes & $41(6.3)$ & $23(7.1)$ & $18(5.8)$ & \multirow[t]{2}{*}{0.25} \\
\hline No & $590(93.7)$ & $300(92.9)$ & $290(94.2)$ & \\
\hline \multicolumn{5}{|c|}{ Head of house employment status } \\
\hline Employed & $301(47.5)$ & $158(48.9)$ & $143(46.4)$ & \multirow[t]{2}{*}{0.27} \\
\hline Unemployed & $330(52.5)$ & $165(51.1)$ & $165(53.6)$ & \\
\hline \multicolumn{5}{|l|}{ Health status } \\
\hline Good to Excellent & $418(66.2)$ & $208(64.4)$ & $210(68.2)$ & \multirow[t]{2}{*}{0.16} \\
\hline Poor to Fair & $213(33.8)$ & $115(35.6)$ & $98(31.8)$ & \\
\hline \multicolumn{5}{|l|}{ Years in contact with $\mathrm{HC}$} \\
\hline Up to 2 years & $154(24.4)$ & $82(25.4)$ & $72(23.4)$ & \multirow[t]{3}{*}{0.28} \\
\hline $3-4$ years & $69(10.9)$ & $30(9.3)$ & $39(12.6)$ & \\
\hline$>4$ years & $408(64.7)$ & $211(65.3)$ & $197(64.0)$ & \\
\hline \multicolumn{5}{|c|}{ Contact times with $\mathrm{HC}$ in past 2 years } \\
\hline $0-4$ times & $215(34.1)$ & $107(33.1)$ & $108(35.1)$ & \multirow[t]{2}{*}{0.30} \\
\hline $5-9$ times & $171(27.1)$ & $81(25.1)$ & $90(29.2)$ & \\
\hline$>10$ times & $245(38.8)$ & $135(41.8)$ & $110(35.7)$ & 0.06 \\
\hline \multicolumn{5}{|l|}{ Chronic condition } \\
\hline Yes & $254(39.6)$ & $139(43.0)$ & $115(36.7)$ & \multirow[t]{2}{*}{0.06} \\
\hline No & $377(60.4)$ & $184(57.0)$ & $193(63.3)$ & \\
\hline
\end{tabular}

had visited their health center at least 5 times within two years. 39.6\% reported having a chronic condition and $33.8 \%$ indicated poor to fair health.
Table 2 also shows that the socio-demographic characteristics of sample 1 and 2 had no statistical difference across all parameters. 


\section{Exploratory factor analysis (EFA)}

Initially, the factorability of the 106 items was examined on the one half of the data set. Firstly, it was observed that all the items correlated at least 0.3 with at least one other item. Secondly, the Kaiser-Meyer-Olkin measure of sampling adequacy was calculated to be 0.72 , above the commonly recommended value of 0.6 and Bartlett's test of sphericity was significant $\left(X^{2}(4278)=10,951.7, p<.01\right)$. Finally, the communalities were above 0.3 for 101 items, further confirming that most items shared some common variance with others. Given these overall indicators, factor analysis was deemed to be suitable with all 106 items.

\section{Construct validity}

Results of the rotated matrix after principal axis factoring, varimax rotation and Kaiser normalization are found in Additional file 1. Seven common factors were extracted based on the initial exploratory factor analysis and were named first contact - access, continuity of care (communication), continuity of care (personal relationship), coordination, comprehensiveness (services available), comprehensiveness (services provided) and community orientation. Initial item reduction was based on the scree test and then retaining items with factor loadings of at least 0.32 , items sharing the same underlying meaning of construct without cross loadings of the same significance and inter-item correlation between 0.2 and 0.5. As a result, from the preliminary number of items those retained were as follows: 3 of the 18 items in the first contact - access domain, 4 of the 7 items in the continuity of care (communication) domain, 4 of the 9 items in continuity of care (personal relationship) domain, 3 of the 13 items in the coordination domain, 6 of the 28 items in the comprehensiveness (services available) domain, 6 of the 19 items in the comprehensiveness (services provided) domain and 3 items from the community orientation domain.

As shown in Table 3, factor loadings ranged from 0.34 to 0.89 . The coordination domains were analyzed separately to include only those patients that had experienced referral.

\section{Internal consistency}

The Cronbach's alpha coefficient results ranged from 0.66 (first contact) to 0.91 (coordination) for all revised multiitem scales. The item-total correlations ranged from 0.31 to 0.87 , meeting the acceptable standard of $>0.30$ (Table 3 ).

\section{Likert scale assumptions}

Tables 3 and 4 show the results of Likert scaling assumptions using the seven revised multi-item scales. All itemscale correlations were above the accepted minimum (0.30) with the majority being greater than 0.50 . All scales demonstrated a relatively narrow range of item-scale correlations. Five of the seven scales showed $100 \%$ discriminant validity. The two comprehensiveness available and comprehensives provided had items that correlated higher in other scales but were retained because of other favorable metric properties.

\section{Confirmatory factor analysis (CFA)}

The structural equation model (SEM) for sample 2 is illustrated in Fig. 2. After allowing for some covariations between unique variables, this model produced a satisfactory goodness of fit to the model: chi squared test $=462.59$, $\mathrm{df}=270, \mathrm{CMIN} / \mathrm{df}=1.71, p=<0.001, \mathrm{GFI}=0.90, \mathrm{CFI}=$ 0.91, RMSEA $=0.05$, PCLOSE $=0.65$.

\section{Descriptive features of PCAT-mw}

Table 5 presents estimates of central tendency, dispersion, and other features of the seven revised scales representing four core primary care principles and one derivative domain. The full range of possible scores was observed for all scales. Continuity (personal relationship) and the two comprehensiveness domains were positively skewed, indicating distributions with more negative ratings of primary care. The other four scales were negatively skewed indicating more positive ratings among patients.

\section{Further reliability}

Forty four out of 50 patients $(88 \%)$ returned for a second interview at the intra -rater reliability chosen facility while

Table 3 Results of exploratory factor analysis ${ }^{a}$ and internal consistency $(n=323)$ of PCAT-Mw

\begin{tabular}{lllll}
\hline Scale & $\begin{array}{l}\text { Number of retained } \\
\text { items/original items }\end{array}$ & $\begin{array}{l}\text { Factor loadings on } \\
\text { the scale }\end{array}$ & $\begin{array}{l}\text { Item-total correlation } \\
\text { range }\end{array}$ & $\begin{array}{c}\text { Cronbach's alpha } \\
\text { First contact- access }\end{array}$ \\
Continuity of care - communication & $3 / 18$ & $0.34-0.59$ & $0.31-0.62$ & 0.66 \\
Continuity of care- personal relationship & $4 / 7$ & $0.36-0.62$ & $0.39-0.56$ & 0.73 \\
Coordination & $3 / 13$ & $0.47-0.70$ & $0.53-0.63$ & 0.78 \\
Comprehensiveness -services available & $6 / 28$ & $0.81-0.89$ & $0.78-0.87$ & 0.91 \\
Comprehensiveness -services provided & $6 / 14$ & $0.34-0.52$ & $0.42-0.46$ & 0.71 \\
Community orientation & $3 / 6$ & $0.50-0.68$ & $0.43-0.59$ & 0.80 \\
Total & $29 / 95$ & $0.41-0.57$ & $0.49-0.67$ & 0.78 \\
\hline
\end{tabular}

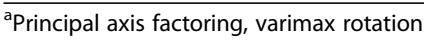


Table 4 Results of item convergent and discriminant validity testing ( $n=323)$ of PCAT-Mw

\begin{tabular}{lllll}
\hline Scale & Number of items & Item- scale correlation & Item- other scale correlation & Scaling success rate (\%) \\
\hline First contact - access & 3 & $0.31-0.65$ & $0.03-0.21$ & $21 / 21=100 \%$ \\
Continuity of care - communication & 4 & $0.46-0.72$ & $0.01-0.41$ & $28 / 28=100 \%$ \\
Continuity of care - personal relationship & 4 & $0.34-0.70$ & $0.10-0.33$ & $28 / 28=100 \%$ \\
Coordination & 3 & $0.69-0.81$ & $0.02-0.41$ & $21 / 21=100 \%$ \\
Comprehensiveness- services available & 6 & $0.33-0.65$ & $0.07-0.39$ & $40 / 42=95 \%$ \\
Comprehensiveness- services provided & 6 & $0.31-0.92$ & $0.03-0.39$ & $46 / 49=94 \%$ \\
Community orientation & 3 & $0.36-0.52$ & $0.05-0.38$ & $21 / 21=100 \%$ \\
\hline
\end{tabular}

42 out of 50 patients $(84 \%)$ returned for a second interview at the inter - rater chosen facility. A high level of reliability was found between the sum scores of the domain mean scores in both the intra-rater test re-test and the inter-rater reliability. The Intra-class Correlation Coefficient (ICC) for the intra-rater test re-test was 0.90 with a $95 \%$ confidence interval (CI) of $0.81-0.95(n=44, p<0.001)$. The ICC for inter-rater reliability was $0.84,95 \%$ CI $0.71-0.96(n=$ $42, p<0.001)$.

The final version of the adult PCAT-Mw questionnaire is attached as Additional file 2.

\section{Discussion}

This study developed a 29 item PCAT-Mw with seven scales as a tool for measuring the performance of primary care from adult patients' experience in the Malawian context. The items in the PCAT-Mw measure the four core dimensions of primary care: first contact - access, continuity of care, coordination and comprehensiveness of services as well as the derivative dimension of community orientation. The PCAT-Mw is significantly shorter making it time efficient in administration and will contribute to the evaluation of primary care performance in Malawi.

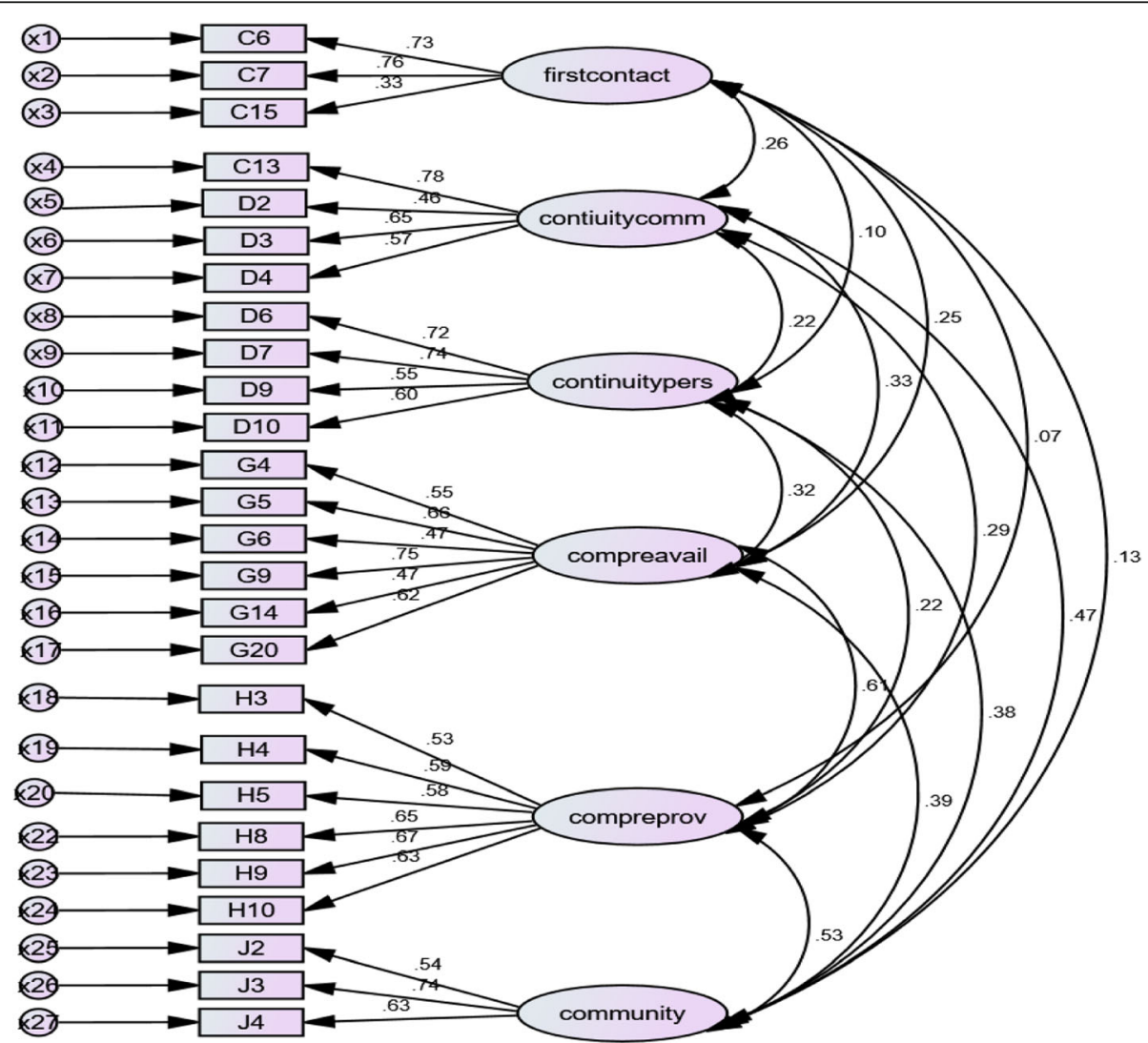

Fig. 2 Structural equation model of Sample 2, $n=308$, with imposed equality constraint of 1 on the factors 
Table 5 Descriptive features of PCAT-M

\begin{tabular}{|c|c|c|c|c|c|c|c|c|c|}
\hline Scale & $\begin{array}{l}\text { Number } \\
\text { of items }\end{array}$ & Mean & $\begin{array}{l}\text { Standard } \\
\text { deviation }\end{array}$ & $\begin{array}{l}\text { 25th } \\
\text { percentile }\end{array}$ & $\begin{array}{l}\text { 50th } \\
\text { percentile }\end{array}$ & $\begin{array}{l}\text { 75th } \\
\text { percentile }\end{array}$ & Range & Skewness & Kurtosis \\
\hline First contact - access & 3 & 8.48 & 2.44 & 7 & 9 & 10 & $3-12$ & -1.62 & 0.32 \\
\hline Continuity of care-communication & 4 & 14.53 & 2.53 & 9 & 16 & 16 & $4-16$ & -.2 .18 & 3.84 \\
\hline Continuity of care- personal relationship & 4 & 9.26 & 4.26 & 4 & 7 & 16 & $4-16$ & 0.99 & -1.68 \\
\hline Coordination & 3 & 9.64 & 3.43 & 8 & 12 & 12 & $3-12$ & -1.14 & -0.54 \\
\hline Comprehensiveness - services available & 6 & 14.5 & 5.01 & 7 & 12 & 23 & $6-24$ & 0.38 & -1.04 \\
\hline Comprehensiveness - services provided & 6 & 22.25 & 5.86 & 15 & 28 & 28 & $7-28$ & 1.09 & -0.36 \\
\hline Community orientation & 3 & 11.80 & 3.79 & 7 & 16 & 16 & $4-16$ & -0.65 & 1.36 \\
\hline
\end{tabular}

Accepted methods of cross-cultural adaptation were carried out on the South African version. The resultant PCAT-Mw underwent standard metric analyses to assess reliability and validity. The high ICC observed for both intra-rater and inter-rater reliability could be due to the fact that the PCAT-Mw measures patients' experience rather than satisfaction with care and that the 4 weeks' interval was optimal for repeat measurements.

The dimension of coordination was not included in the structural equation model (SEM) because of limited data as only $16 \%$ of patients reported to have been referred to a higher level of care. However confirmatory factor analysis performed on the items under first contact - access, continuity of care, comprehensiveness of services and community orientation yielded results that indicated that the retained items sufficiently represented the conceptual multidimensional nature of primary care. Models of these core dimensions and the one derivative dimension of community orientation showed satisfactory statistical fit.

This also supports the idea that the creation of effective primary care systems is context dependent and that the strength of a country's primary care system is determined by the degree of development of a combination of core primary care dimensions in the context of its health care system $[46,47]$. With regards to Likert scale assumptions, the two comprehensiveness scales had some items that correlated with other scales. However, the other five scales achieved $100 \%$ item-other scale discriminant validity, and the other Likert scaling assumptions, including item convergent validity, equal item-scale correlation, and score reliability, were satisfied, which suggests by and large the appropriateness of the usage of the Likert scales in this study which can be used without standardization.

PCAT-Mw is different in the factor structure from the original PCAT adult expanded version and ZA-PCAT on which adaptation was based. The original version consists of four core dimensions represented by six scales and three derivative domains while the South African version has an additional derivative domain "the primary care team". Nonetheless, the final PCAT-Mw scales are consistent with the theoretical four core principles of primary care. While the domain "primary care team" was eliminated at content validity stage, "family orientation" and "cultural competence" did not satisfy metric analysis requirements for retention similar to other studies [30-32].

There are a number of ways in which a reliable and valid tool such as the PCAT-Mw would be applied in health services research. This study shows that although primary care in Malawi is structured differently, it does conform to the accepted definition and reflects the multi-dimensionality as proposed by the Institute of Medicine [35]. The instrument can be used to assess the content and organization of primary care in Malawi in the regions where Chichewa is the main language. Another application is the use of the PCAT-Mw to set the standards of quality of primary care based on data on patients' experience of service delivery. In this regard, the PCAT-Mw can be used on its own as well as in combination with clinical outcome measures. Users of the PCAT-Mw should review the adequacy and relevance of the comprehensiveness domains to the context in which they are to be applied. Similarly, those items that showed lower item-total correlation may be considered to be used when more information on accessibility is desired.

The study had a number of potential limitations. First is that although an adequate sample size as confirmed by the Kaiser-Meyer-Olkin and Bartlett's test results, the study was carried out in one rural district, which may limit its generalizability to the national scale particularly in those regions where people largely speak another language other than Chichewa. This currently accounts for about $35 \%$ of the population. Cross cultural adaption will be needed when another language should be used. Another potential limitation on generalizability is the exclusion of acutely ill, frail and patients with severe mental illness. Further studies should consider different settings to include patients that initially presented with conditions that needed immediate attention to assess their experience of primary care. Second is the potential for recall bias inherent with this nature of studies. The intra-rater and inter-rater reliability tests and the one to one interviewing sought 
to ascertain minimal measurement error that would arise from it.

The PCAT-Mw is a new instrument in this setting. However, it is based on a standardized and widely used questionnaire and a full validation procedure was undertaken. Further, future application of the tool in more regions and populations could add to its validation on a wider scale. Future studies could also develop tools for providers, managers and children to provide a comprehensive assessment of primary care as was developed in the original set of tools and could combine this methodology and disease specific quality of care measurement.

\section{Conclusion}

This study indicates that the PCAT Mw is a reliable and valid tool to assess core concepts of primary care as seen from patients' perspective in Malawi. It can be used to establish baseline and to compare primary care performance from patients' perspectives over time. Further studies could focus on assessing responsiveness and developing tools for providers, managers and children and to compare measures of patients' experiences with disease specific outcomes in Malawi.

\section{Additional files}

Additional file 1: Exploratory factor analysis of PCAT-Mw - Rotated factor matrix after principal axis factoring, varimax rotation with Kaiser normalization. This presents the factor loadings of each item and the number of factors extracted after initial factor analysis. (DOCX $35 \mathrm{~kb}$ )

Additional file 2: Primary care assessment tool Malawi adult version (PCAT-Mw). This is the final validated PCAT-Mw with 29 items in English and the local language Chichewa and socio-demographic data and health care questions. (DOCX $188 \mathrm{~kb}$ )

\section{Abbreviations}

CFA: Confirmatory Factor Analysis; CFI: Comparative Fit Index; Cl: Confidence Interval; EFA: Exploratory Factor Analysis; GFl: Goodness of Fit Index; ICC: Intra-class correlation coefficient; PCAT - Mw: Primary Care Assessment Tool - Malawian version; PCAT: Primacy Care Assessment Tool; PCLOSE: P value of close fit; RMSEA: Root Mean Squared Error of Approximation; SEM: Structural Equation Model; ZA-PCAT: Primary Care Assessment Tool - South African version

\section{Acknowledgements}

The authors thank the participants in the survey and the expert panel for their enormous contribution towards this study. Special mention goes to Dr. Graham Bresick for providing insights in the initial processes of the study, Constance Kantema for her role in translation and data collection; Joe Lusaka and Beth Dunbar in the back translation process.

\section{Funding}

Funding for the study was provided by Partners In Health and The University of Bergen. The Principal Investigator and corresponding author is employed by Partners In Health and a PhD student at the University of Bergen.

\section{Availability of data and materials}

The datasets use and/or analyzed during the current study are available from the corresponding author on reasonable request.

\section{Authors' contributions}

LD conceived, designed and carried out the study, the data analysis and drafting of the paper. EM took part in the development of the study, the analysis, interpretation of data and critically revised the paper. SG took part in the development of the study, supported interpretation of the results and critically revised the paper. $\varnothing \mathrm{H}, \mathrm{TM}$ and SG supported interpretation of the results and critically revised the paper. All authors read and approved the final paper.

Ethics approval and consent to participate

Ethical approval for the study was provided by the Malawi National Health Sciences Research Committee as part of the protocol "Evaluation of Clinical care in Neno." The District Health Officer and heads of facilities also provided approval. Study participants provided written consent.

\section{Competing interests}

The authors declare that they have no competing interests.

\section{Publisher's Note}

Springer Nature remains neutral with regard to jurisdictional claims in published maps and institutional affiliations.

\section{Author details}

'Department of Global Public Health and Primary Care, University of Bergen, Bergen, Norway. ${ }^{2}$ Partners In Health, Neno, Malawi. ${ }^{3}$ University of Malawi College of Medicine, Blantyre, Malawi.

Received: 21 September 2017 Accepted: 2 May 2018

Published online: 16 May 2018

\section{References}

1. Shi L. The relationship between primary care and life chances. J Health Care Poor Underserved. 1992;3(2):p321-35.

2. Starfield B. Primary care: is it essential? Lancet. 1994;344(8930):p1129-33.

3. Shi L. Primary care, specialty care, and life chances. Int J Health Serv. 1994; 24(3):p431-58.

4. Franks P, Fiscella K. Primary care physicians and specialists as personal physicians: health care expenditures and mortality experience. J Fam Pract. 1998;47(2):p105-9.

5. Farmer FL, Stokes C, Fiser R, Papini DP. Poverty, primary care and agespecific mortality. The Journal of Rural Health. Spring. 1991;7(2):153-69.

6. Shi L, Starfield B. Primary care, income inequality, and self-rated health in the United States: a mixed-level analysis. Int J Health Serv. 2000;30(3):p541-55.

7. Starfield B, Shi L, Macinko J. Contribution of primary care to health systems and health. Milbank Q. 2005;83(3):457-502.

8. WHO. World Health Report: Primary health care (now more than ever). World Health Organisation; 2008. http://www.who.int/whr/2008/en/ Accessed 25 May 2017.

9. Bresick G, Sayed A, le Grange C, et al. Western cape primary care assessment tool (PCAT) study: measuring primary care organization and performance in the western Cape Province, South Africa. Afr J Prm Health Care Fam Med. 2016;8(1):a1057. https://doi.org/10.4102/ phcfm.v8i1.1057.

10. Wei $X, L i H$, Yang $N$, et al. Comparing quality of public primary care between Hong Kong and shanghai using validated patient assessment tools. PLoS One. 10(3):e0121269. https://doi.org/10.1371/journal. pone.0121269.

11. Hu R, Liao Y, Du Z, et al. Types of health care facilities and the quality of primary care: a study of characteristics and experiences of Chinese patients in Guangdong Province, China. BMC Health Serv Res. 2016;16:335. Available on : doi. https://doi.org/10.1186/s12913-016-1604-2.

12. Browne $K$, Roseman $D$, Shaller $D$, et al. Analysis \& commentary measuring patient experience as a strategy for improving primary care. Health Aff. 2010;29:921-5.

13. Malawi Government Ministry of Health. Health sector strategic plan II 2017-22. Lilongwe; 2017. Available on www.health.gov.mw/index.php/policiesstrategies?download=47:hssp-ii-final ( Accessed on 21 July, 2017)

14. WHO. Malawi factsheet of health statistics, 2016: WHO-AFRO; 2016. Available on http://aho.afro.who.int/profiles_information/images/d/d8/MalawiStatistical_Factsheet.pdf. Accessed 25 May 2017.

15. Abiiro GA, Mbera GB, De Allegri M. Gaps in universal health coverage in Malawi: a qualitative study in rural communities. BMC Health Serv Res. 2014; 14:234. Available from http://www.biomedcentral.com/1472-6963/14/234 (Accessed on 20 Feb 2017)

16. Zere $\mathrm{E}$, Moeti M, Kiringa J, et al. Equity in health and healthcare in Malawi analysis of trends. BMC Public Health. 2007;7:78. Available from https:// 
bmcpublichealth.biomedcentral.com/articles/10.1186/1471-2458-7-7. Accessed 12 Feb 2017.

17. Swanepoel M, Mash B, Naledi T. Assessment of the impact of family physicians in the district health system of the western cape, South Africa. Afr J Prim Health Care Family Med. 2014;6(1):8. https://doi.org/10.4102/ phcfm.v6i1.695. pages. Art. 695

18. Mash R, Ogunbanjo G, Naidoo $S$, et al. The contribution of family physicians to district health services: a national position paper for South Africa. South Afr Fam Pract. 2015;57(3):p54-61. S

19. Kidd $\mathrm{M}$. The contribution of family medicine to improving health systems: a guidebook from the world Organization of Family Doctors, Second Edition. p. 10-21.

20. Wroe EB, Kalanga N, Mailosi B, et al. Leveraging HIV platforms to work toward comprehensive primary care in rural Malawi: the integrated chronic care clinic, healthcare; 2015. https://doi.org/10.1016/j.hjdsi.2015.08.002i.

21. Dullie L, Wroe E B, Dunbar E et al Evaluating the impact of a community health worker program in Neno, Malawi (protocol). https://clinicaltrials.gov/ ct2/show/NCT03106727.

22. Watson $\mathrm{SI}$, Wroe EB, Dunbar EL, et al. The impact of user fees on health services utilization and infectious disease diagnoses in Neno District, Malawi: a longitudinal, quasi-experimental study. BMC Health Serv Res. 2016;16:595. https://doi.org/10.1186/s12913-016-1856-x.

23. Flocke SA. Measuring attributes of primary care: development of a new instrument. J Fam Pract. 1997;45:64-74.

24. Safran DG, Kosinske M, Tarlov AR, et al. The primary care assessment survey: tests of data quality and measurement performance. Med Care. 1998;36:728-39.

25. Casady CE, Starfield B, Hurtado MP, et al. Measuring consumer experiences with primary care. Pediatrics. 2000;105:998-1003.

26. Shi L, Starfield B, Xu J. Validating the adult primary care assessment tool. J Fam Pract. 2001;50:161.

27. Mead $\mathrm{N}$, Bower $\mathrm{P}$, Roland $\mathrm{M}$. The general practice assessment questionnaire (GPAQ) - development and psychometric characteristics. BMC Fam Pract [serial online]. 2008;9:13. http:// www.biomedcentral.com/1471-2296/9/13

28. Barker I, Steventon A, Deeny SR. Association between continuity of care in general practice and hospital admissions for ambulatory care sensitive conditions: cross sectional study of routinely collected, person level data. BMJ. 2017;356:j84. https://doi.org/10.1136/bmj.j84.

29. Pasarin Ml, Berra S, Rajmil $\mathrm{L}$, et al. An instrument to evaluate primary health care from the population perspective. Aten Primaria. 2007;39(8):395-401.

30. Pasarin MI, Berra S, Gonzalez A, et al. Evaluation of primary care: the "primary care assessment tools - facility version" for the Spanish health system. Gac Sanit. 2013;27(1):12-8. https://doi.org/10.1016/.gaceta.2012.03.009.

31. Yang $H$, Shi L, Lebrun $L$, et al. Development of the Chinese primary care assessment tool: data quality and measurement properties. Int J Qual Health Care. 2013;25(1):92-105.

32. Lee $\mathrm{JH}$, Choi $\mathrm{YH}$, Sung $\mathrm{NJ}$, et al. Development of the Korean primary care assessment tool-measuring user experience: tests of data quality and measurement performance. Int J Qual Health Care. 2009;21 (2):103-11.

33. Aoki T, Inoue M, Nakayama T. Development and validation of the Japanese version of primary care assessment tool. Fam Pract. 2016;33(1):112-7. https://doi.org/10.1093/fampra/cmv087.

34. Bresick G, Sayed A, Le Grange C, et al. Adaptation and cross-cultural validation of the United States primary care assessment tool (expanded version) for use in South Africa. Afr J Prim Health Care Fam Med. 2015;7(1) https://doi.org/10.4102/phcfm.v7i1.783.

35. Institute of Medicine. Defining primary care: an interim report. Washington: National Academy Press; 1994.

36. Hsu C, Sandford BA. The Delphi technique: making sense of Consensus Practical Assessment Research \& Evaluation. 2007;12(10) Available online: http://pareonline.net/getvn.asp? $=12 \& n=10$

37. McMillan SS, King M, Tully MP. How to use the nominal group and Delphi techniques. Int J Clin Pharm. 2016;38:655-62. https://doi.org/10.1007/ s11096-016-0257-x.

38. De Vet HCW, Terwee CB, Mokkink LB, et al. Measurement in Medicine. A Practical Guide. Cambridge CB2 8BS. United Kingdom: Cambridge University Press; 2011. p. 155

39. Beavers AS, Lounsbury JW, Richards JK, et al. Practical considerations for using exploratory factor analysis in educational research. Pract Assess Res Eval. 2013;18(6) Available online: http://pareonline.net/getvn.asp?v=10\&n=7

40. Bartlett MS. A note on multiplying factors for various chi square approximations. J R Stat Soc. 1954;16(Series B):296-8.
41. Osborne JW, Costello AB. Best practices in exploratory factor analysis: four recommendations for getting the best out of your analysis. Pan-Pacific Manag Rev. 2009;12(2):136-45.

42. McIntosh CN. Improving the evaluation of model fit in confirmatory factor analysis: A commentary on Gundy CM, Fayers PM, Groenvold M, Petersen MAa, Scott NW, Sprangers MAJ, Velikov G, Aaronson NK. Comparing higherorder models for the EORTC QLQ-C30. 2011; Quality of Life Research. 2012; 21(9):1619-21. https://doi.org/10.1007/s11136-011-0082-6.

43. Schumacker RE, Lomax RG. A beginner's guide to structural equation modelling ( $\left.2^{\text {nd }} E d\right)$. Mahwah: Lawrence Erlbaurn Associates, Inc.; 2004.

44. Marsh HW, Balla JR, McDonald RP. Goodness of fit indexes in confirmatory factor analysis: the effect of sample size. Psychol Bull. 1998;103:391-410.

45. Hu L, Bentler PM. Cutoff criteria for fit indexes in covariance structure analysis: conventional criteria versus new alternatives. Struct Equ Model Multidiscip J. 1999:6:1. https://doi.org/10.1080/10705519909540118.

46. Kringos DS, Boerma WGW, Hutchinson A, et al. BMC Health Serv Res. 2010; 10:65. http://www.biomedcentral.com/1472-6963/10/65

47. Martin R. Measuring and improving patient experience in primary care. Prim Health Care Res Dev. 2012;13(2):103-5. https://doi.org/10.1017/ $\$ 1463423612000084$

\section{Ready to submit your research? Choose BMC and benefit from:}

- fast, convenient online submission

- thorough peer review by experienced researchers in your field

- rapid publication on acceptance

- support for research data, including large and complex data types

- gold Open Access which fosters wider collaboration and increased citations

- maximum visibility for your research: over $100 \mathrm{M}$ website views per year

At BMC, research is always in progress.

Learn more biomedcentral.com/submissions 